\title{
Effect of Sportive Activity on Bone Mineral Density during Adolescence
}

\author{
Yavuz SAYAR, Fatma İnci ARIKAN, Medine Ayşin TAŞAR, Yıldız DALLAR \\ Clinic of Pediatrics, Ankara Training and Research Hospital, Ankara, Turkey
}

\begin{abstract}
Objective: This study aims to evaluate the effect of performance of regular sportive activity (SA) on bone mineral density in adolescents. Material and Methods: Fifty-five adolescents performing regular SA and 56 normally active adolescents were included in the study. Bone mineral density was measured with a quantitative ultrasonography device.

Results: Adolescents performing regular SA had higher bone mineral density when compared with normally active adolescents ( $p=0.011)$. Vitamin $D$ levels were also higher in the group performing regular SA $(p<0.001)$. Children of parents with higher educational status were significantly related with higher prevalence of performance of regular SA.

Conclusion: Performing regular physical activity during adolescence is important for bone mineral density, and children should be encouraged to perform regular SA in the early period.

Keywords: Adolescents, bone mineral density, quantitative ultrasound, physical activity
\end{abstract}

\section{Introduction}

Childhood period, particularly puberty, has critical role in the protection of bone health and prevention of adulthood osteoporosis. The principal factor affecting adulthood bone health is peak bone mass that is achieved during puberty $(1,2)$.

Hormonal balance, genetic structure, calcium/vitamin D metabolism, nutrition, lifestyle, and physical activity are the fundamental factors affecting bone health. Puberty period is very important to prevent osteoporosis that has become one of the most important problems with the increasing sedentary lifestyle of our age $(3,4)$.

The World Health Organization defined osteoporosis and osteopenia for postmenopausal women. Since there is no con- sensus on the criteria regarding childhood osteoporosis, the term "reduced bone mass for age" is accepted as a definition. Evaluation of estimated bone mineral density (eBMD) is recommended for diagnosis of reduced bone mass in children $(3,4)$.

Several methods have been used to evaluate eBMD in children. When compared with other methods, it has been found that quantitative ultrasound is safe, easy to perform, and lacks radiation; therefore, it can be used to evaluate eBMD in children $(5,6)$.

This study aimed to evaluate the difference of eBMD between adolescents who perform and do not perform regular sportive activity (SA) by quantitative ultrasound. Factors, such as anthropometric measurements, nutrition, calcium, vitamin $D$, and biochemical parameters, that may have an impact on eBMD were also evaluated. 


\section{Material and Methods}

Healthy adolescents admitted to the Department of Pediatrics for one-year period were included in this study. The study protocol was approved by the local ethics committee, and written informed consent was provided by each patient. Adolescents aged between 9 and 18 years were enrolled in the two groups according to performance of regular SA $(n=55)$ (Group 1) and normally active $(n=56)$ (Group 2$)$. Adolescents who performed regular SA with license for at least one year were included in Group 1. Regular SAs included football, basketball, volleyball, swimming, judo, and athletics.

Parents of adolescents were informed before the study, and informed consent was obtained from all parents. Patients with chronic diseases were not included in the study.

Daily calcium consumption was weekly calculated with dietary milk, milk products (milk, cheese, and yogurt), and fish intake (7). Preterm delivery, history of fractures, coke and spirit intake (glasses and more/day use was considered), vitamin use, history of smoking, age of onset of menorrhea for girls, and dressing styles were recorded. Duration of sun exposure and time spent watching television and playing the computer were also recorded in terms of minutes.

All adolescents were evaluated for height, body weight, and body mass index (BMI) with percentiles (8). Body mass index was calculated with the formula $\mathrm{kg} / \mathrm{m}^{2}$ (9). Heights were measured in the upright position. During height measurements, patients stood in front of the height chart by taking care to touch their head, back, hip, and heel to the height charts. The same device was used for body weight measurement of all subjects. Body weight measurements were measured when the subjects were undressed and before they were fed. Tanner stages of patients were recorded.

To evaluate bone metabolism, serum calcium (Ca), phosphorus $(\mathrm{P}), 25(\mathrm{OH})$ vitamin $\mathrm{D}$, calcitonin, osteocalcin, parathyroid hormone (PTH), and alkaline phosphatase (ALP) levels were evaluated. Venous blood samples were investigated for $\mathrm{Ca}, \mathrm{P}$, ALP, and $25(\mathrm{OH})$ vitamin D levels. Serum Ca, P, and ALP levels were analyzed with photometric method using the original Olympus kit in an analyzer of Olympus AU640 (Japan). The reference range for Ca was 8.8-10.6 mg/dL, P was 4-7 mg/dL, and ALP was 74-390 IU/L.

Radioimmunoassay analysis of $25(\mathrm{OH})$ vitamin $D$ is performed with the GAMMA-C12 analyzer (Gama Counter DPC, USA) with a reference range of $10-80 \mathrm{ng} / \mathrm{mL}$. Parathyroid hormone (parathormone intact) was measured with chemiluminescent methods with the Beckman Coulter's Unicel DxI 800 analyzer (USA). Reference range for parathyroid hormone was 14-72 pg/ $\mathrm{mL}$. Calcitonin and osteocalcin levels were evaluated with the ELISA method with an automatic microelisa device (Radim, Alisei, Italy). Reference ranges for calcitonin and ostecalcin were 0-150 pg/mL and 1.5-15 ng/mL, respectively.

The quantitative ultrasonography device (Sunlight Omnisense 7000 Premier) was used to measure eBMD. Estimated
BMD levels were assessed by calculating the $Z$ score and speed of sound (SOS, m/sn) levels. Measurements were performed with the CMC6317 probe of Sunlight Omnisense 7000 Premier from the distal radius of the non-dominant arm. For the measurement, the patient was seated and the arm was placed perpendicular to the table. The midpoint between the elbow and third was finger marked. After applying the gel on the distal radius, the central place of the CM probe that is used for the pediatric population was placed parallel to bone on the marked line. To provide a contact area, a light pressure with the probe was directly contacted in the region. By applying a slight pressure to provide direct contact, the probe was held with both hands on the region that we performed the measurement. The measurement was initiated with the device by moving the probe in $70^{\circ}$ downward and upward direction. Three best measurement

Table 1. Comparison of different variables in Groups 1 and 2

\begin{tabular}{lccc} 
Variables & $\begin{array}{c}\text { Group 1 } \\
(\mathbf{n}=55)\end{array}$ & $\begin{array}{c}\text { Group 2 } \\
(\mathbf{n}=56)\end{array}$ & $\mathbf{p}$ \\
\hline $\begin{array}{l}\text { Mother's education } \\
\text { (High School and University), } \mathrm{n}(\%)\end{array}$ & $14(25.5)$ & $1(1.8)$ & 0.002 \\
$\begin{array}{l}\text { Father's education } \\
\text { (High School and University), } \mathrm{n}(\%)\end{array}$ & $17(30.9)$ & $5(8.9)$ & 0.018 \\
$\begin{array}{l}\text { Vitamin use, n (\%) } \\
\text { Coke consumption, n (\%) }\end{array}$ & $13(23.7)$ & $1(1.8)$ & 0.002 \\
Smoking, $\mathrm{n}(\%)$ & $39(70.9)$ & $44(78.6)$ & $>0.05$ \\
Sun exposure, $\mathrm{n}(\%)$ & 0 & $5(8.9)$ & 0.023 \\
$\quad<30$ min. & & & \\
$\quad 30-60$ min. & $4(7.2)$ & $5(8.9)$ & \\
$\quad>60$ min. & $20(36.4)$ & $30(53.6)$ & $>0.05$ \\
& $31(56.4)$ & $21(37.5)$ &
\end{tabular}

Time spent at watching TV and/or playing computer games, $\mathrm{n}(\%)$

$<30$ min. $\quad 1(1.7) \quad 1(1.8)$

30-60 min $\quad 2(3.6) \quad 6(10.9)$

60-120 min $10(17.9) \quad 10(18.3)$

$>0.05$

120-180 min. $\quad 19(33.9) \quad 19(34.5)$

$>180$ min. $\quad 24(42.9) \quad 19(34.5)$

Body mass index $\left(\mathrm{kg} / \mathrm{m}^{2}\right)$, mean \pm SD $\quad 19.6 \pm 2.2 \quad 20.6 \pm 2.5 \quad 0.024$

Calcium consumption, $\mathrm{n}(\%)$

0-500 mg $\quad 9(16.3) \quad 13(23.2)$

500-1000 mg $26(47.3) \quad 29(51.8)$

$>1000 \mathrm{mg} \quad 20(36.4) \quad 14(25.0) \quad>0.05$

25(OH) Vitamin $D(\mathrm{ng} / \mathrm{mL}), \quad \quad 47 \quad 33.5 \quad 0.001$

median (min-max)

$(32.0-69.3) \quad(17.0-42.4)$

Calcitonin $(\mathrm{pg} / \mathrm{mL})$ median (min-max)

$4.6 \quad 7.5$

(3.4-8.2) (3.8-13.9)

$\mathrm{BMD}$ ( $Z$ score ), mean $\pm \mathrm{SD}$

$+0.298 \pm 1.101 \quad-0.298 \pm 1.000 \quad 0.011$

$\operatorname{SOS}(\mathrm{m} / \mathrm{s})$, mean \pm SD

$3860 \pm 1451 \quad 3820 \pm 1970>0.05$

Percentile (\%) median

(min-max)

65

41

0.017

$(31.0-88.0) \quad(21.6-69.0)$ 
cycles were obtained. The value was expressed as $\mathrm{m} / \mathrm{sn}$ for the average of at least three measurements (10).

\section{Statistical Analysis}

These studies were performed with a simple random sampling. The data obtained from the study was analyzed with Statistical Package for the Social Sciences (SPSS Inc., Chicago, IL, USA) 15.0. The Kolmogorov-Smirnov test was used to evaluate the normal distribution of variables. The data with normal distribution were given with the mean \pm standard deviation, and the ones without normal distribution were expressed as the median with interquartile ranges. Nominal variables were shown as the number of observations and percentages. Data with normal distribution were compared in groups with the Student's t-test. The data without normal distribution and two sampled comparisons were compared with the Mann-Whitney $U$ test and Chi-square test. Spearman correlation was used for correlation analysis. To define the factors affecting physical activity, multivariate logistic regression analysis was used. In multivariate logistic regression analysis, parameters, including age, educational status of mother and father, and vitamin supplementation use, that

\section{Table 2. Distribution of sportive activities}

\begin{tabular}{lc} 
Variables & $\mathbf{n}=55(\%)$ \\
\hline Football & $20(36.4)$ \\
Basketball & $1(1.8)$ \\
Volleyball & $9(16.4)$ \\
Swimming & $19(34.5)$ \\
Judo & $4(7.3)$ \\
Athletics & $2(3.6)$
\end{tabular}

Table 3. Comparison of groups for osteopenia scores (Z scores $<-1$ )

\begin{tabular}{lcc} 
Variables & $\begin{array}{c}\text { Group 1 } \\
\mathbf{n}=55,(\%)\end{array}$ & $\begin{array}{c}\text { Group 2 } \\
\mathbf{n}=56,(\%)\end{array}$ \\
\hline No osteopenia & $47(85.5)$ & $45(80.4)$ \\
Osteopenia & $8(14.5)$ & $11(19.6)$
\end{tabular}

were used in univariate analysis were used as covariate; $p$ values $<0.05$ was considered significant.

Included in this study we will as the statistical method to determine the number of volunteers, the PASS program package was used; alpha $=0.05$ and power $=0.80, \mathrm{n}=110$ was calculated to be.

\section{Results}

Fifty-five adolescents in Group 1 and 56 adolescents in Group 2 were included in the study. There was no difference between the two groups in terms of age, gender, and Tanner stage ( $p>0.05)$.

Vitamin supplementation uses were significantly higher in Group 1, whereas smoking was higher in Group 2. Daily calcium consumption did not show any difference between the groups. Group 1 measured vitamin D levels higher than Group $2(\mathrm{p}<0.001)$ (Table 1$)$.

Sporting activity of adolescents included in the study were football $(n=20,34.6 \%)$, and swimming $(n=19,34.5 \%)$ (Table 2). Because of the numbers of football players and swimmers that is more than the other groups, between these two groups did not show any significant difference for BMI, Ca, ALP, PTH, Vitamin D, calcitonin, eBMD, and SOS ( $p>0.05)$.

No statistical difference was detected between the groups for osteopenia score (Z score<-1) (Table 3). Sporting activity increases eBMD ( $Z$ score) but does not statistically reduce osteopenia.

No statistical difference was detected in SOS and eBMD between gender, parental education, vitamin consumption, smoking, sun exposure, cola consumption, time for watching TV, playing computer, and calcium consumption ( $p>0.05$ ). Vitamin D levels and BMI were not correlated with eBMD and SOS ( $p>0.05)$.

In evaluation multivariate regression analysis for factors affecting physical activity, educational status of mothers with high school and university degree increased the possibility of performing regular physical activity in adolescents by 12.2 fold ( $\mathrm{Cl}$ 95\%: 1.441-104.005, $\mathrm{p}=0.022$ ). Furthermore, vitamin supplementation use increased the possibility of physical activity by 10.9 folds ( $\mathrm{Cl} 95 \%$ : 1.264-95.301, $\mathrm{p}=0.030$ ) (Table 4).

Table 4. Multivariate regression analysis for factors affecting physical activity

\begin{tabular}{|c|c|c|c|c|c|c|}
\hline Variables & \multicolumn{3}{|c|}{ Univariate } & \multicolumn{3}{|c|}{ Multivariate } \\
\hline $\begin{array}{l}\text { Educational status of mother } \\
\text { (High school/University) }\end{array}$ & 18.780 & $2.373-148.634$ & 0.005 & 12.242 & $1.441-104.005$ & 0.022 \\
\hline $\begin{array}{l}\text { Educational status of father } \\
\text { (Higher school/University) }\end{array}$ & 4.563 & $1.547-13.464$ & 0.006 & - & - & - \\
\hline Vitamin use & 17.024 & $2.141-135.347$ & 0.007 & 10.977 & $1.264-95.301$ & 0.030 \\
\hline
\end{tabular}




\section{Discussion}

Osteoporosis is a multi-factorial disease causing progressive loss of bone mass and increase risk of fractures $(6,11)$. Physical activity during growth increases the peak bone mass. Appropriate exercise programs improve the growth of skeletal system while growing (12).

It has been reported that within a healthy weight range there is a direct, positive relationship between BMI and bone density (13). In our study, BMI was higher in adolescents who did not perform regular SA. However, no correlation was found in BMI and eBMD and SOS.

Parental support and socio-economic status significantly affects physical activity in adolescents (14). We found that adolescents performing regular SA had higher parental educational status. Multivariate regression analysis revealed that educational status of mothers increases the possibility of physical activity by 12.2 folds.

The study performed in Lebanon demonstrated that adolescents with low socio-cultural levels had decreased eBMD values (15). In Turkey, a study investigating the relationship between eBMD and socio-economic status revealed that boys in high socio-economic status schools had higher $Z$ scores on quantitative ultrasound examinations (16). In our study, although the parent's economic status was not evaluated, there was no correlation between the parents' education and eBMD.

It has been confirmed that Ca supplementation influenced bone density in women during pubertal growth (17). A study evaluating the relationship between calcium intake and bone mineralization found a positive association between calcium intake and higher $Z$ scores (18). Another study demonstrated that calcium intake has no effect on bone density (19). In our study, we could not find a positive relation between calcium consumption and eBMD. We noticed that adolescents with performance of regular SA consumed more calcium-containing nutrients as an indicator of healthy nourishment. However, adolescents included in this study consumed less than required daily calcium (1300 mg/day).

It has been reported that there is a positive correlation between $25(\mathrm{OH})$ Vitamin D levels and physical activity during adolescence (20). Moreover, it has been confirmed that vitamin D levels were significantly associated with physical activity in 559 adolescents aged between 14 and 18 years (21). In our study, vitamin D levels significantly increased in adolescents performing regular SA when compared with those in normally active adolescents. Multi-vitamin pills were more consumed by adolescents performing regular SA that is considered to be an indicator of healthy life. Multivariate regression analysis of factors affecting physical activity demonstrated that vitamin supplementation increased the possibility of physical activity by 10.9 folds. Some countries similar to ours have a high incidence of vitamin D deficiency. Therefore, these results suggest that nutritional supplementations with calcium-rich nutrients and vitamin $D$ can be recommended for bone health in these countries.

A study reported that children participating in SAs in school have a $1.2 \%$ higher bone density than children with normally active (22). Cvijetić et al. (19) found a positive correlation between physical activity and bone density in a study among 501 children and adolescents with quantitative ultrasonographic analysis of eBMD. Our results are compatible with literature and confirm that physical activity during adolescence significantly increases eBMD. These results suggest that adolescents should be encouraged to perform physical activity, and SAs in schools should be improved in quality and quantity. We found that $76.8 \%$ of adolescents who did not perform regular SA spent $>2$ $\mathrm{h}$ watching television and playing computer games daily. However, this was observed in $69 \%$ of adolescents performing regular SA. Sedentary lifestyle has become common among our population. Because countries with younger populations are under the risk of osteoporosis, parents and educationists should take account of all preventive strategies and provide more areas for SAs.

A study suggests that the type of sportive activity has an influence on the peak bone density and decreased osteoporosis risk (23). Falk et al. (24) reported that SOS values obtained from the non-dominant arm of gymnasts was significantly higher than those of swimmers and controls. A study from China enrolled subjects into groups according to their sporting activities and measured eBMD with quantitative ultrasound. Estimated BMD was found to be higher in football players and dancers when compared with swimmers and adolescents with sedentary lifestyles (25). In Turkey, eBMD was found to be higher in football players and dancers when compared with that in normally active individuals $(26,27)$. In our study, the most common SAs were playing football and swimming. When the results of adolescents were compared between football players and swimmers, eBMD and SOS values did not show any significant difference. These results can be explained by the limited number of cases included in our study.

A study performed in Finland revealed that adolescents with decreased vitamin $D$ levels had also decreased eBMD values measured on radial sites (24).

\section{Conclusion}

However, osteoporosis is considered to be an adulthood disease, and recent studies demonstrated that it can be preventable during childhood. Although several methods are used to evaluate the bone health, the ideal method is still controversial. All of these methods have advantages and disadvantages. An ideal method should be inexpensive, easy to perform, and should have limited exposure to radiation. Although, further studies are required, quantitative ultrasound method has positive correlation with eBMD in children. In particular, we think that physical activity during adolescence can reduce the risks in the future. This suggests that SA should be encouraged in the early life. Furthermore, it has been revealed that adolescents with high educational status of parents had significantly increased physical activity and better nutritional status. Therefore, our belief is to improve educational status in our country.

Ethics Committee Approval: Ethics commitee approval was received for this study from the ethics commitee of Ankara Training and Research Hospital. 
Informed Consent: Written informed consent was obtained from patients who participated this study.

Peer-review: Externally peer-reviewed.

Author Contributions: Concept - Y.S.; Design - Y.S., M.A.T., F.I.A., Y.D.; Supervision -F.I.A.,Y.D.; Resource - Y.S., F.I.A.; Materials - Y.S., F.I.A., Y.D.; Data Collection and/or Processing - Y.S., M.A.T.; Analysis and/or Interpretation - Y.S., F.I.A, Y.D., M.A.T.; Literature Review - Y.S., F.I.A., M.A.T.; Writer - Y.S., F.I.A., M.A.T., Y.D.; Critical Review -F.I.A., Y.D.

Conflıct of Interest: No conflıct of interest was declared by the authors

Financial Disclosure: The authors declared that this study has received no financial support.

\section{References}

1. Loud KJ, Gordon MC. Adolescent Bone Health. Arch Pediatr Adolesc Med 2006;160:1026-32. [CrossRef]

2. Hartman C, Hochberg Z, Shamir R. Osteoporosis in pediatrics. Isr Med Assoc J 2003;5:509-15.

3. Coker M. Çocuk Kemik Sağlığı. Güncel Pediatri Dergisi 2008;6:1213.

4. Saggese G, Baroncelli GI, Bertolloni S. Osteoporosis in children and adolescents; diagnosis, risk factors and prevention. J Ped Endocrinol Metab 2001;14:833-59. [CrossRef]

5. Baroncelli GI. Quantitative ultrasound methods to assess bone mineral status in children: technical characteristics, performance and clinical application. Pediatric Res 2008;63:220-8. [CrossRef]

6. Özkan B, Döneray H. Çocuklarda osteoporoz. Güncel Pediatri 2006;2:1-7.

7. Baysal A, Keçelioğlu S, Arslan P. Besinlerin Bileşimleri. Türkiye Diyetisyenler Derneği Yayını. 3. Baskı Ankara; 1991: p.6-18.

9. Gahagan S. Overweight and obesity. In: Kliegman R, Stanton B, St. Geme J, Schor N, Behrman RE, eds. Nelson Textbook of Pediatrics, 19th. Edition Philadephia: Elsevier Saunders; 2011: p.179. [CrossRef]

10. Weiss M, Ben-Shlomo AB, Hagag P, Rapoport M. Reference database for bone speed of sound measurement by a novel quantitative multi-site ultrasound device. Osteoporos Int 2000;11:688-96. [CrossRef]

11. Kohrt WM, Bloomfield SA, Little KD, Nelson ME, Yingling VR; American College of Sports Medicine. Physical and bone health. Med Sci Sports Exerc 2004;36:1985-96. [CrossRef]

12. Bailey DA, Faulkner RA, Mckay HA. Growth, physical activity and bone mineral acquisition. Exerc Sport Sci Rev 1996;24:233-66. [CrossRef]

14. Raudsepp L. The relationship between socio economic status, parental support and adolescent physical activity. Acta Pediatr 2006;95:93-8. [CrossRef]

15. Arabi $A$, Nabulsi $M$, Maaulof J, Choucair $M$, Khalifé $H$, Vieth $R$, et al. Bone mineral density by age, gender, pubertal stages, and so- cioeconomik status in healthy Lebanese children and adolescent. J Ortop Sports Phys Ther 2004;35:1169-79. [CrossRef]

16. Gökçe-Kutsal $Y$, Atalay A, Sonel-Tur B. Effect of socio-economic status on bone density in children: comparison of two schools by quantitative ultrasound measurement. J Pediatr Endocrinol Metab 2007;20:53-8. [CrossRef]

17. Matkovic V, Goel PK, Badenhop-Stevens NE, Landoll JD, Li B, Ilich Z], et al. Calcium supplemention and bone mineral density in females from childhood to young adult: a randomized controlled trial. Am J Clin Nutr 2005;81:175-88.

18. Prais D, Diamond G, Kattan A, Salzberg J, Inbar D. The effect of calcium intake and physical activity on bone quantitative ultrasound measurements in children: a pilot study. J Bon Miner Metab 2008;26:248-53. [CrossRef]

19. Cvijetić S, Barić IC, Bolanca S, Juresa V, Ozegović DD. Ultrasound bone measurement in children and adolescents: Correlation with nutrition, puberty, antropometry and physical activity. J Clin Epidemiol 2003;56:591-7. [CrossRef]

20. Gordon M, DePeter KC, Feldman HA, Grace E, Emans SJ. Prevalence of vitamin $\mathrm{D}$ deficiency among healthy adolescents. Arch Pediatr Adolesc Med 2004;158:531-7. [CrossRef]

21. Dong Y, Pollock N, Stallmann-Jorgensen IS, Gutin B, Len L, Chen TC, et al. Low 25 hydroxyvitamin $D$ levels in adolescents: race, season, adiposity, physical activity and fitness. Pediatrics 2010;125:110411. [CrossRef]

22. McKay HA, Petit MA, Schutz RW, Prior JC, Barr SI, Khan KM, et al. Augmented trochanteric bonemineral density after modified physical education classes: a randomized school-based exercise intervention study in prepubescent and early pubescent children. J Pediatr 2000;136:156-62. [CrossRef]

23. Andreoli A, Monteleone M, Van Loan M, Promenzio L, Tarantino $U$, De Lorenzo A, et al. Effects of different sports on bone mineral density and muscle mass in highly trained athletes. Med Sci Sports Exerc 2001;33:507-11. [CrossRef]

24. Falk B, Brohnstein Z, Zigel L, Constantini NW, Eliakim A. Quantitative ultrasound of the tibia and radius in prepubertal and earlypubertal Female athletes. Arch Pediatr Adolesc 2003;157:139-43. [CrossRef]

25. Yung PS, Lai YM, Tung PY, Tsui HT, Wong CK, Hung VWY, et al. Effects of weight bearing and non-weight bearing exercises on bone properties using calcaneal quantitative ultrasound. $\mathrm{Br}$ J Sports Med 2005;39:547-51. [CrossRef]

26. Tarakçi D, Oral A. How do contralateral calcaneal quantitative ultrasound measurements in male professional football players reflect the effects of high-impact physical activity on bone? J Sports Med Phys Fitness 2009;49:78-84.

27. Oral A, Tarakçi D, Dişçi R. Calcaneal quantitative ultrasound measurements in young male and female professional dancers. J Strength Cond res 2006;20:572-8. [CrossRef] 


\title{
Susceptibility of the Median Palmar Cutaneous Nerve in Carpal Tunnel Syndrome
}

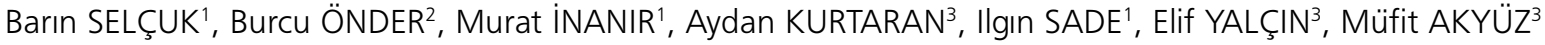 \\ 'Deparment of Physical Medicine and Rehabilitation, Kocaeli University Faculty of Medicine, Kocaeli, Turkey \\ ${ }^{2}$ Clinic of Physical Medicine and Rehabilitation, Çorlu State Hospital, Çorlu, Turkey \\ ${ }^{3}$ Clinic of Physical Medicine and Rehabilitation, Ankara Physical Medicine and Rehabilitation Training and Research Hospital, Ankara, Turkey
}

\begin{abstract}
Objective: The aim of this study was to investigate the susceptibility of the palmar cutaneous branch of median nerve (PCBm) in carpal tunnel syndrome (CTS).

Material and Methods: Electrophysiological assesment of the PCBm sensory conduction study in electrodiagnostically defined carpal tunnel syndrome extremities.

Results: We examined 83 hands with electrodiagnostically defined CTS and 33 control extremities. While none of the extremities without carpal tunnel syndrome shows pathological PCBm sensory conduction study, $62.7 \%$ (52) of the extremities with carpal tunnel syndrome showed pathologic conduction and there was statistically significant difference between the groups $(p<0.05)$. PCBm sensory nerve action potential (SNAP) was obtained in all of the extremities with mild carpal tunnel syndrome. The SNAP could not be obtained in 20\% (5/25) extremities with moderate carpal tunnel syndrome and in extremities with $46.1 \%(6 / 13)$ severe carpal tunnel syndrome. On evaluation according to the severity of carpal tunnel syndrome; $37.2 \%(16 / 43)$ of the cases with mild carpal tunnel syndrome showed electrophysiological pathology in PCBm sensory conduction study, and it was detected in $92.6 \%(27 / 25)$ of the cases with moderate carpal tunnel syndrome, and $84.6 \%(11 / 13)$ of the cases with severe carpal tunnel syndrome

Conclusion: PCBm is frequently effected in patientes with CTS and suggest that this nerve not ideal as a comparator nerve for the electrophysiological diagnosis of CTS.

Keywords: Median palmar cutaneous nerve, carpal tunnel syndrome, electrophysiology, ENMG
\end{abstract}

\section{Introduction}

Carpal tunnel syndrome (CTS) is the most common peripheral mononeuropathy with a development risk rate of $10 \%$ during the whole life (1). It is a frequently seen syndrome characterized by pain, numbness, and a tingling sensation in the hands due to the compression of the median nerve in the wrist (2). In CTS, typical sensory distribution is restricted to the volar aspect of the palm, the first 3 fingers, and the lateral region of the $4^{\text {th }}$ finger. The protection of the thenar area innervated by the palmar cutaneous branch of the median nerve $(\mathrm{PCBm})$ that branches before entering the carpal tunnel is important in clinical and electrophysiological evaluations (3).

The palmar cutaneous branch of the median nerve branches off before the median nerve enters the carpal tunnel, and it provides sensory innervations of the thenar region; therefore, it is not affected by CTS (4). Owing to this feature, studies comparing $\mathrm{PCBm}$ with the main median nerve are recommended

Address for Correspondence: Barın Selçuk, MD, Kocaeli Üniversitesi Tıp Fakültesi, Fiziksel Tıp ve Rehabilitasyon Anabilim Dalı, Kocaeli, Türkiye. Phone: +90 2623038633 E-mail: barinselcuk@yahoo.com

Received: January 2014 Accepted: April 2014

OCopyright 2015 by Turkish Society of Physical Medicine and Rehabilitation - Available online at www.ftrdergisi.com

Cite this article as: 